\title{
STUDYING THE EFFECT OF TWO TYPES OF SALT IN PROGRESSION OF CHRONIC RENAL FAILURE IN RATS
}

\author{
Esraa M. Awad-Allah ; Ahmed A. Ameen and Alaa O. Aboraya \\ Nutrition and Food Science Department, Faculty of Home Economics, Helwan \\ University, Cairo, Egypt.
}

Key Words: chronic kidney disease, rock salt, refined salt, rats.

\section{ABSTRACT}

Salt ingestion has been linked to kidney disease via hemodynamic (increased introglomerular pressure) and non-hemodynamic mechanisms (increased oxidative stress), independent of blood pressure. The aim of the present study was to compare the effect of rock salt (Halite) to refined salt in different concentrations on chronic renal failure rats. Thirty adult male Sprague-Dawley rats which weighing $(170 \pm 5 \mathrm{~g})$ were divided randomly into two main groups as follow: the first group (-ve control= 5 rats) was fed on basal diet. The second group (25 rats) were fed on $14 \%$ casein diet containing $0.7 \%$ adenine for 4 weeks to induce chronic kidney disease (CKD), then divided into 5 subgroups from group 2 to group 6 . Subgroup 2 (+ve control) fed on basal diet. Subgroup 3 and 4 fed on basal diet supplemented with $4 \%$ and $8 \%$ of refined salt, respectively. Subgroup 5 and 6 fed on basal diet supplemented with $4 \%$ and $8 \%$ of rock salt, respectively. At the end of the experimental period (4 weeks), rats were scarified and serum was collected to determine kidney functions. The results showed that serum concentrations of creatinine, urea, uric acid, sodium and potassium were significantly elevated $(\mathrm{P}<0.05)$ by adenine administration (positive control) compared to negative control, in contrast, serum total protein, albumin and globulin were significantly reduced $(\mathrm{P}<0.05)$. Also, it was indicated that rock salt administration recorded the best changes for these parameters in CKD rats compared to refined salt. It be concluded that restriction of sodium intake is an important preventive and therapeutic measure in patients with chronic renal diseases or at risk of renal damage such as hypertensive. So, it be recommended to use rock salt instead of refined salt and further studies are required to elucidate beneficial effect and the mechanism of how rock salt attenuates blood pressure.

\section{INTRODUCTION}

Chronic kidney disease (CKD) is an important, widespread clinical problem which has multiple etiologies. Control of blood pressure, cholesterol, and glucose are important strategies to slow progression of CKD towards end-stage renal disease (ESRD) (Walker $\boldsymbol{e}$ t al., 1989).

The common sources of salt for consumers can be classified into refined (table) salt, sea salt, rock salt, and processed salt (Lee $\boldsymbol{e t}$ al., 
2007). The relationship between salt and blood pressure has been discussed in medical literature for decades and it has been shown that increased salt intake contributes to the prevalence of hypertension and proteinuria (Swift et al., 2005).

Less intensely studied are the direct nephrotoxic effects of sodium chloride. Salt ingestion has been linked to kidney disease via hemodynamic (e.g. increased introglomerular pressure) and nonhemodynamic mechanisms (e.g. increased oxidative stress), independent of blood pressure (Weir and Fink, 2005).

Although there is growing awareness by the general public of the health benefits of rock salt, there is little information on whether consumption of rock salt can have a direct effect on blood pressure and CKD (Chanumuang, 2010).

The aim of the present study was to compare the effect of rock salt (Halite) to refined salt in different concentrations on chronic renal failure rats.

\section{MATERIALS:}

\section{MATERIALS AND METHODS}

Rock salt and refined salt in the form of powder, were purchased from El-Gomhoriya Pharm., Cairo, Egypt. Adult male Sprague-Dawley rats $(n=30)$ which weighing $(170 \pm 5 \mathrm{~g})$ were purchased from Farm of experimental animals in Helwan, Egypt. Adenine, casein, all vitamins, minerals, cellulose, choline and starch were obtained from El-Gomhoria Company, Cairo, Egypt.

\section{METHODS:}

\section{1- Induction of CKD in rats:}

Rats were inducted with chronic renal failure by using the method described by (Yokozawa et al., 1986) by feeding rats on $14 \%$ casein diet containing $0.7 \%$ adenine for 4 weeks.

\section{2- Preparation of salts:}

Salts were grinded, then the powder was mixed with basal diet in different levels.

\section{3- Diet composition and experimental animal design:}

The basal diet was formulated according to AIN-93M diet (Reeves et al., 1993). Animals (30 rats) were housed in well conditions in biological studies lab of Faculty of Home Economics. They were left for seven days as adaptation period and they were allowed to feed standard laboratory food and water. After the period of adaptation, animals were divided into two main groups, as follows: - the first group (5 rats) was fed on basal diet and served as a negative control group (ve), the second group (25 rats) was fed on $14 \%$ casein diet containing $0.7 \%$ adenine for 4 weeks. After chronic renal failure rats were divided as follow:- 
Subgroup (1): Five Rats with chronic kidney disease (CKD rats) were fed on basal diet as positive control group $(+\mathrm{Ve})$.

Subgroup (4): $\quad$ Five CKD Rats were fed on basal diet supplemented with $4 \%$ Refined salt (Replacement with salt in basal diet).

Subgroup (5): $\quad$ Five CKD Rats were fed on basal diet supplemented with $8 \%$ Refined salt (Replacement with salt in basal diet).

Subgroup (2): $\quad$ Five CKD Rats were fed on basal diet supplemented with $4 \%$ Rock salt (Replacement with salt in basal diet).

Subgroup (3): $\quad$ Five CKD Rats were fed on basal diet supplemented with $8 \%$ Rock salt (Replacement with salt in basal diet).

At the end of the experimental period ( 4 weeks), rats were fasted overnight before scarifying and blood samples were collected from each rat and were centrifuged at $3000 \mathrm{rpm}$ for $15 \mathrm{~min}$ to obtain the serum for biochemical analysis.

\section{4- Biological evaluation:}

Feed intake (FI), body weight gain percentage (BWG \%) and feed efficiency ratio (FER) were determined according to Chapman $\boldsymbol{e t}$ al., (1959) using the following equation:

BWG\% = Final body weight - Initial body weight $/$ Initial body weight $\times 100$

$$
\text { FER = Weight gain } / \text { Feed intake. }
$$

\section{5- Chemical Analysis of Rock Salt and Refined Salt:}

Chemical analysis of rock salt and refined salt were done in Agriculture Research Center and determined according to method describe by Ranganna, (1977).

\section{6- Biochemical analysis of serum:}

Serum uric acid was determined in the serum according to method describe by Milena, (2003). Serum urea nitrogen, creatinine and total Protein were determined in the serum according to method describe by Burtis and Ashwood, (1999). Serum potassium and Serum sodium were determined according to method describe by Hoeflmayr, (1979). Albumin and globulin were determined in the serum according to method describe by Young, (2001) and Goldenberg and Drewes, (1971), respectively. Serum sodium and potassium were determined according to method describe by Guder, et al., (1982) and Hoeflmayr, (1979).

\section{7- Statistical Analysis:}

Results were expressed as the mean standard error \pm SE. Data were statistically analyzed for variance "ANOVA" test at $\mathrm{P} \leq(0.05)$ 
using SPSS statistical software, version 20 was used for these calculations (Armitage and Berry, 1987).

\section{RESULTS AND DISCUSSION}

Data in Table (1) showed the chemical analysis of of rock salt and refined salt, it was observed that rock salt contained $87.98 \%$ of $\mathrm{NaCl}$ while refined salt contained $99.9 \%$ of $\mathrm{NaCl}$.

Lee et al., (2017) reported that rock salt that contains $85.7 \% \mathrm{NaCl}$ whereas refined salt contained $99.9 \% \mathrm{NaCl}$. In addition to sodium, rock salt also contains calcium $(1.5 \mathrm{mg} / \mathrm{g})$, potassium $(2.9 \mathrm{mg} / \mathrm{g})$, magnesium $(3.9 \mathrm{mg} / \mathrm{g})$, and traces amounts of iron, manganese and zinc.

Table 1: Chemical Analysis of Rock Salt and Refined Salt

\begin{tabular}{|l|c|}
\hline Sample & NaCl\% \\
\hline Rock salt & 87.98 \\
\hline Refined salt & 99.9 \\
\hline
\end{tabular}

Results recorded in Table (2) showed the effect of rock salt and refined salt on body weight gain (BWG), feed intake (FI) and feed efficiency ratio (FER) in CKD rats. It was observed that FI, BWG and FER significantly decreased in positive control compared to negative control. Group that fed on refined salt recorded the lower reduction in FI, BWG and FER than group fed on rock salt. Group that fed on $4 \%$ rock salt recoded the lowest reduction in FI, BWG and FER compared to positive control.

Table (2): Effect of Rock Salt and Refined Salt on Feed Intake (FI), Body Weight Gain\% (BWG \%) and Feed Efficiency Ratio (FER) of Chronic Renal Failure Rats

\begin{tabular}{|c|c|c|c|}
\hline $\begin{array}{l}\text { Groups } \\
\text { Parameters }\end{array}$ & FI (g/d) & BWG\% & FER \\
\hline Negative Control & 16.5 & $21.91 \pm 1.44^{\mathrm{a}}$ & $0.070 \pm 0.004^{a}$ \\
\hline Positive Control & 15.2 & $9.11 \pm 0.30^{b}$ & $0.030 \pm 0.001^{b}$ \\
\hline 8\% Refined Salt & 11.55 & $3.15 \pm 0.17^{d}$ & $0.018 \pm 0.002^{d}$ \\
\hline 4\% Refined Salt & 14 & $4.50 \pm 0.44^{\mathrm{cd}}$ & $0.020 \pm 0.001^{c d}$ \\
\hline $8 \%$ Rock Salt & 13.5 & $4.18 \pm 0.34^{\text {cd }}$ & $0.018 \pm 0.002^{d}$ \\
\hline 4\% Rock Salt & 14.15 & $6.05 \pm 0.43^{c}$ & $0.026 \pm 0.003^{b c}$ \\
\hline
\end{tabular}

*Mean values are expressed as means $\pm \mathrm{SE}$.

* Mean values at the same column with the same superscript letters are not statistically significant at $\mathbf{P}<0.05$.

Results of BWG were in the same line with Lee et al., (2017), who found that the final body weight in the group that fed on the high level of refined salt was significantly lower than all other groups. In the current study, feed intake of refined salt group was the lowest compared to the rock salt group. This was due to larger amount of food consumption by the rock salt groups despite the refined salt diet 
containing a higher salt content than the rock salt diet. The fact that rock salt diets were consumed at a higher rate than the refined salt diets may be an indication that the chow with rock salt was more palatable to the rats (Lee et al., 2017).

As showed in Table (3), serum creatinine, urea and uric acid were elevated significantly $(\mathrm{P}<0.05)$ elevated by adenine administration in positive control group compared to the negative control group. It was observed that the group that fed on high level of refined salt $(8 \%)$ recorded the most increase in serum creatinine, urea and uric acid levels compared to all groups. While the rock salt group (4\%) recorded the lower increase in these parameters than other groups that treated with the different levels of salts compared to positive control group.

Concerning results of kidney functions in were confirmed by Saad et al., (2018), who showed that adenine administration significantly increased serum urea, creatinine and uric acid. Salt intake is associated with the development of impaired kidney function in the general population, independent of its effects on blood pressure (Sugiura et al., 2018). Rock salt contains trace amounts of natural minerals such as $\mathrm{MgSO} 4, \mathrm{CaSO} 4, \mathrm{CaCl} 2$ and $\mathrm{KCl}$ with slightly lower sodium content compared to refined salt. Although there is growing awareness by the general public of the health benefits of rock salt, there is little information on whether consumption of rock salt can have a direct effect on blood pressure regulation (Chanmuang, 2010).

Table (3): Effect of Rock Salt and Refined Salt on Serum Creatinine, Urea and Uric Acid of Chronic Renal Failure Rats

\begin{tabular}{|c|c|c|c|}
\hline Parameters & Creatinine & Urea & Uric Acid \\
\hline Groups & \multicolumn{3}{|c|}{ mg/dL } \\
\hline Negative Control & $0.62 \pm 0.05^{f}$ & $23.15 \pm 0.43^{e}$ & $2.75 \pm 0.75^{\mathrm{e}}$ \\
\hline Positive Control & $0.91 \pm 0.09^{\mathrm{e}}$ & $30.05 \pm 0.29^{d}$ & $3.11 \pm 0.04^{d}$ \\
\hline 8\% Refined Salt & $1.14 \pm 0.04^{\mathrm{a}}$ & $35.63 \pm 0.31^{\mathrm{a}}$ & $5.79 \pm 0.10^{\mathrm{a}}$ \\
\hline 4\% Refined Salt & $0.96 \pm 0.06^{c}$ & $33.22 \pm 0.30^{b}$ & $4.62 \pm 0.80^{b}$ \\
\hline 8\% Rock Salt & $0.98 \pm 0.05^{b}$ & $35.16 \pm .48^{\mathrm{a}}$ & $4.59 \pm 0.84^{b}$ \\
\hline $4 \%$ Rock Salt & $0.93 \pm 0.06^{d}$ & $31.15 \pm 0.20^{c}$ & $3.42 \pm 0.13^{c}$ \\
\hline
\end{tabular}

*Mean values are expressed as means $\pm \mathrm{SE}$.

*Mean values at the same column with the same superscript letters are not statistically significant at $P<0.05$.

Results in Table (4) showed a significant $(\mathrm{P}<0.05)$ increased in serum sodium and potassium in positive control by administration of adenine compared to negative control group. Rats that fed on the high level of refined salt $(8 \%)$ recorded the highest elevation in serum $\mathrm{Na}$ and $\mathrm{K}$ compared to other treated groups with salts, while rats that fed on $4 \%$ rock salt recorded the lowest elevation in serum $\mathrm{Na}$ and $\mathrm{K}$. 
Results of potassium were in agreement with Kashioulis $\boldsymbol{e t}$ al., (2018), who reported that plasma concentration of potassium was clearly elevated in rats that treated with adenine. It is known that dietary potassium can influence blood pressure, and that it can play a role in controlling blood pressure in hypertensive patients (Rodrigues et al., 2014). Suzuki et al., (2007) which reported that salt is essential and important for maintaining life. Sodium is an essential nutrient and one of the important cations in the extracellular fluid. Several studies have suggested that excess salt intake deteriorates a renal function and increase in blood pressure. In these regards, modulation of salt is of utmost importance in the fields of hypertension and nephrology (McMahon et al., 2013). Lee et al., (2017) reported that how the rock salt diet actually exerts its anti-hypertensive effects is not clear. One obvious point to consider is the content of minerals other than sodium in the rock salt.

Table (4): Effect of Rock Salt and Refined Salt on Serum Sodium (Na) and Potassium (K) of Chronic Renal Failure Rats

\begin{tabular}{|c|c|c|}
\hline \multirow{2}{*}{ Proups } & $\mathrm{Na}$ & $\mathbf{K}$ \\
\hline & \multicolumn{2}{|c|}{$\mathrm{mg} / \mathrm{dL}$} \\
\hline Negative Control & $142.80 \pm 0.86^{\mathrm{e}}$ & $4.07 \pm 0.04^{e}$ \\
\hline Positive Control & $149.00 \pm 1.14^{\mathrm{d}}$ & $4.60 \pm 0.11^{\mathrm{d}}$ \\
\hline $8 \%$ Refined Salt & $167.00 \pm 1.00^{\mathrm{a}}$ & $7.09 \pm 0.09^{\mathrm{a}}$ \\
\hline 4\% Refined Salt & $153.80 \pm 0.77^{\mathrm{c}}$ & $5.01 \pm 0.04^{c}$ \\
\hline $8 \%$ Rock Salt & $157.99 \pm 0.32^{b}$ & $6.05 \pm 0.0^{b}$ \\
\hline 4\% Rock Salt & $151.20 \pm 0.41^{\mathrm{cd}}$ & $4.61 \pm 0.17^{\mathrm{d}}$ \\
\hline
\end{tabular}

*Mean values are expressed as means $\pm \mathrm{SE}$.

*Mean values at the same column with the same superscript letters are not statistically significant at $\mathbf{P}<0.05$.

Data in Table 5 revealed that serum total protein, albumin and globulin levels were decreased by adenine administration in positive control group compared with the negative control group. Results also illustrated that rats treated with $8 \%$ refined salt recorded the highest reduction in serum total protein, albumin and globulin compared with other treated groups with salts, while rats that fed on $4 \%$ rock salt recorded the lowest reduction in these parameters.

Results of serum total protein and albumin were in agreement with Saad et al., (2018), who reported that the administration with adenine significantly decreased serum albumin and total protein. Salt restriction significantly reduced urinary protein excretion in all studies that reported proteinuria (McMahon et al., 2015). In fact, a recently published double-blind controlled randomized trial in patients with CKD (stages 3 and 4) showed that dietary sodium restriction significantly 
decreased blood pressure, and consistent reductions in proteinuria and albuminuria were shown (McMahon et al., 2013 and Hosohata, 2017).

In conclusion, it would appear that restriction of sodium intake is an important preventive and therapeutic measure in patients with chronic renal diseases or at risk of renal damage such as hypertensive. It is likely that the major beneficial effect of rock salt is associated with the mineral content of the rock salt that is known to be anti-hypertensive such as potassium, calcium and magnesium. It is also possible that there are as yet undetermined component(s) of the rock salt that might confer resistance to hypertension. So, further studies are required to elucidate the mechanism of how rock salt attenuates blood pressure. Based on our findings it would also be important to determine if rock salt consumption would have similar effects on blood pressure in humans.

Table (5): Effect of Rock Salt and Refined Salt on Serum Total Protein, Albumin and Globulin of Chronic Renal Failure Rats

\begin{tabular}{|c|c|c|c|}
\hline Parameters & Total Protein & Albumin & Globulin \\
\hline & \multicolumn{3}{|c|}{ g/dL } \\
\hline Negative Control & $8.84 \pm 0.10^{a}$ & $3.65 \pm 0.13^{a}$ & $2.45 \pm 0.05^{\mathrm{a}}$ \\
\hline Positive Control & $7.58 \pm 0.11^{b}$ & $2.99 \pm 0.07^{b}$ & $2.00 \pm 0.04^{b}$ \\
\hline $8 \%$ Refined Salt & $5.95 \pm 0.13^{d}$ & $0.98 \pm 0.011^{\mathrm{e}}$ & $1.04 \pm 0.03^{c}$ \\
\hline 4\% Refined Salt & $6.71 \pm 0.07^{c}$ & $2.04 \pm 0.2^{d}$ & $1.89 \pm 0.05^{b}$ \\
\hline 8\% Rock Salt & $6.11 \pm 0.04^{d}$ & $1.97 \pm 0.04^{d}$ & $1.17 \pm 0.04^{\mathrm{c}}$ \\
\hline 4\% Rock Salt & $7.03 \pm 0.19^{c}$ & $2.28 \pm 0.12^{c}$ & $1.99 \pm 0.17^{b}$ \\
\hline
\end{tabular}

*Mean values are expressed as means $\pm \mathrm{SE}$.

*Mean values at the same column with the same superscript letters are not statistically significant at $\mathbf{P}<0.05$.

\section{REFERENCES}

Armitage, G.Y. and W.G. Berry (1987): Statistical methods $7^{\text {th }}$ Ed. Ames., Iowa State University. Press.39-63.

Burtis, C. and E. Ashwood (1999): Tietz textbook of clinical chemistry. 3rd ed. Philadelphia:W.B. Saunders, 1999: 1840, 1841, 1844, 1845; 1799; 1834-5 Textbook of Clinical Chemistry, 3rd ed AACC.

Chanmuang, S. (2010): Effects of mineral rich solar salt on blood pressure and insulin action in Dahl salt sensitive rats. Korea, Mokpo National University.

Chanmuang, S. (2010): Effects of mineral rich solar salt on blood pressure and insulin action in Dahl salt sensitive rats. Korea: Mokpo National Universit, Master's thesis.

Chapman, D. G. ; R. Gastilla and J. A. Campbell (1959): Evaluation of protein in foods: 1- A Method for the determination of protein efficiency ratio. Can. J. Biochem. Phys; 37:679- 86. 
Goldenberg, H. and P. Drewes (1971): Direct Photometric Determination of Globulin in Serum. Clinical Chemistery, 17 (5): 358-362.

Guder, W.; Hoffmann, G. and Oppitz, K. (1982): Normalbereiche klin. A normal bere ichklinischer. Chemischer befunde in den Staditischer Krankenhausen Miinchens. Cited in Biochemical Kit.

Hoeflmayr, J. (1979): Comparative photometric calcium determinations with various test. kits. Article in German. Ther Ggw., 118(10): 1577-88.

Hoeflmayr, J. (1979): Comparative photometric calcium determinations with various test. kits. Article in German. Ther Ggw., 118(10): 1577-88.

Hosohata, K. (2017): Biomarkers for Chronic Kidney Disease Associated with High Salt Intake. Int J Mol Sci., 18(10): 1-9.

Kashioulis, P. ; J. Lundgren ; E. Shubbar ; L. Ngu ; A. Saeed ; C. Guron and G. Guron (2018): Adenine-Induced Chronic Renal Failure in Rats: A Model of Chronic Renocardiac Syndrome with Left Ventricular Diastolic Dysfunction but Preserved Ejection Fraction. Kidney Blood Press Res., 43: 1053-1064.

Lee, K.D.; J.W. Park and C.R. Choi (2007): Salinity and heavy metal contents of solar salts produced in Jeollanamdo province of Korea, Korean Soc Food Sci Nutr ;36: 753-758.

Lee, B. ; A. Yang ; M. Kim ; S. McCurdy and W. Boisvert (2017): Natural sea salt consumption confers protection against hypertension and kidney damage in Dahl salt-sensitive rats. Food Nutr Res., 61(1): 1-10.

McMahon, E. ; J. Bauer ; C. Hawley ; N. Isbel ; M. Stowasser ; D. Johnson and K. Campbell (2013): A randomized trial of dietary sodium restriction in CKD. J. Am. Soc. Nephrol., 24: 2096-2103.

McMahon, E. ; K. Campbell1 ; J. Bauer and D. Mudge (2015): Altered dietary salt intake for people with chronic kidney disease. Cochrane Database of Systematic Reviews, 2: 1-48.

Milena, J. S. (2003): predrag Djurdjevic and DejanStankov .JSCS., 68(8-9): 691-698.

Ranganna, S. (1977): Manual of Analysis of Fruit and Vegetable Products. Tata McGraw-Hill, New York.

Reeves, P. ; F. Nielsen and G. Fahmy (1993): AIN-93.Purified diets for laboratory rodents: Final reports of the American Institute of Nutrition adhoe wriling committee of reformulation of the AIN76 A Rodent Diet. J. Nutr., 123:1939-51. 
Rodrigues, S. ; M. Baldo and R. Machado (2014): High potassium intake blunts the effect of elevated sodium intake on blood pressure levels. J Am Soc Hypertens., 8(4): 232-238.

Saad, E. ; H. El-Gayar ; R. El-Demerdash and K. Radwan (2018): Frankincense Administration Antagonizes Adenine-induced Chronic Renal Failure in Rats. Phcog Mag., 14: 634-40.

Sugiura, T. ; H. Takase ; N. Ohte and Y. Dohi (2018): Dietary Salt Intake is a Significant Determinant of Impaired Kidney Function in the General Population. Kidney Blood Press Res., 43: 1245-1254.

Suzuki, H. ; T. Takenaka ; Y. Kanno ; Y. Ohno and T. Saruta (2007): Sodium and Kidney Disease, Nutrition and Kidney Disease: A New Era. Contrib Nephrol. Basel, Karger., 155: 90-101.

Swift, P.A.; N.D. Markandu ; G.A. Sagnella ; F.J. He and G.A. MacGregor (2005): Modest salt reduction reduces blood pressure and urine protein excretion in black hypertensives, a randomized control trial. Hypertension; 46: 308-312.

Walker, I.D.; R.A. Dodds and T.I. Murrells (1989): Restriction of dietary protein and progression of renal failure in diabetic nephropathy. Lancet; 2: 1411-1141.

Weir, M.R. and J.C. Fink (2005): Salt intake and progression of chronic kidney disease: an overlooked modifiable exposure? A commentary, Am J Kidney Dis.;45: 176-188.

Yokozawa, T.; P.D. Zheng ; H. Oura and F. Koizumi (1986): Animal model of adenine-induced chronic renal failure in rats. Nephron., 44 (3):230-234.

Young, D. (2001): Effect of disease on clinical lab Tests, $4^{\text {th }}$ ed. AACC press.

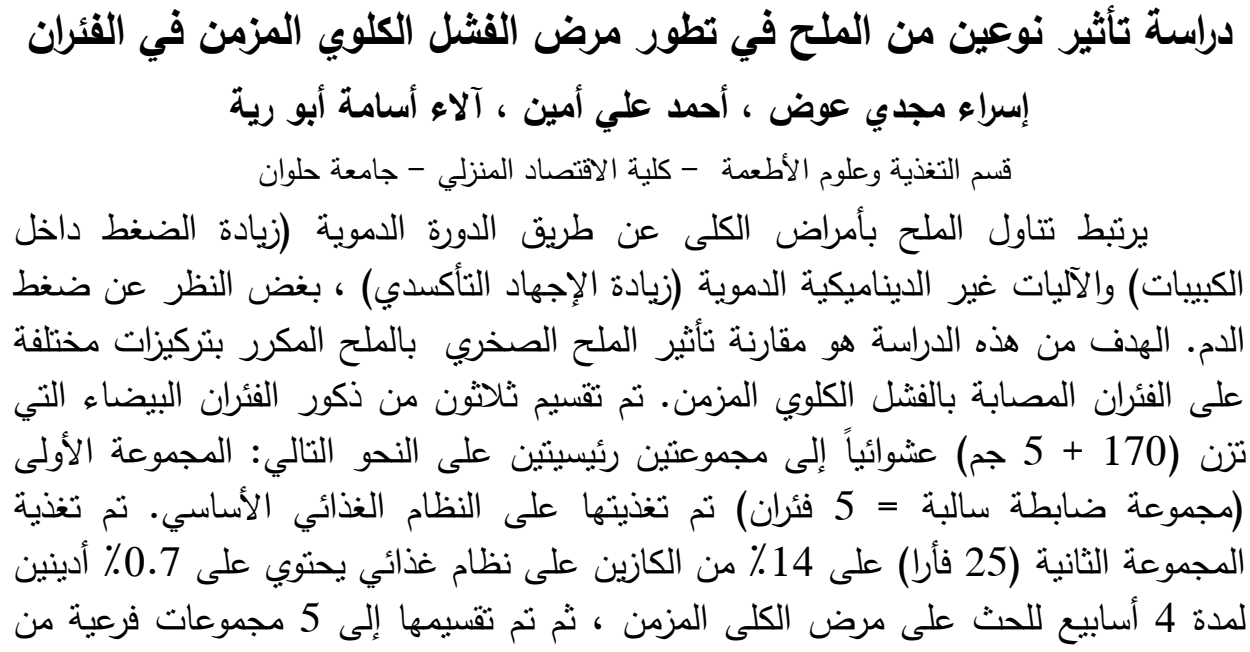


المجموعة 2 إلى المجموعة 6. المجموعة الفرعية 2 (مجموعة ضابطة موجبة) تم تغذيتها على

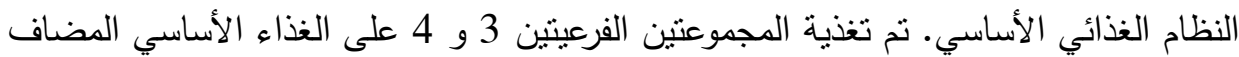

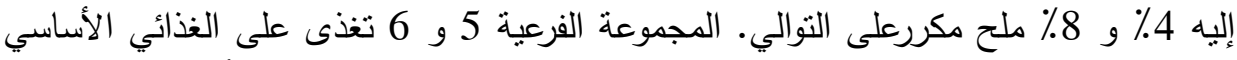

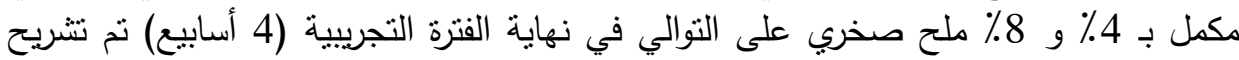

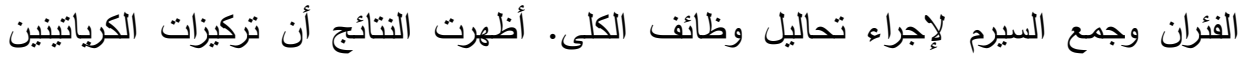

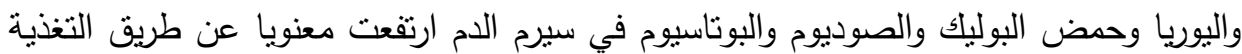

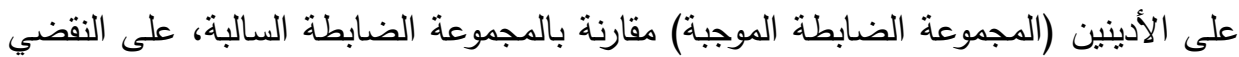
من ذلك انخفض البروتين الكلي في الدم والألبومين والجلوبيولين بشكل ملحوظ. كما تم الإثارة

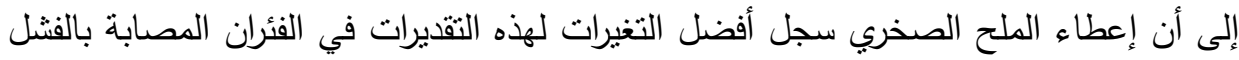

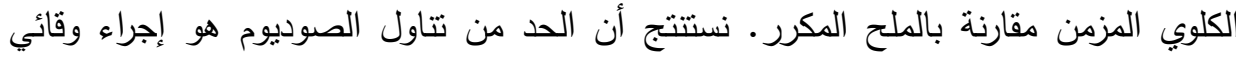

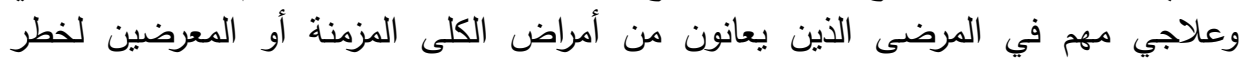

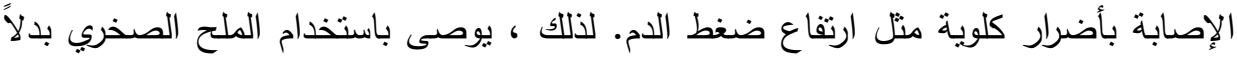

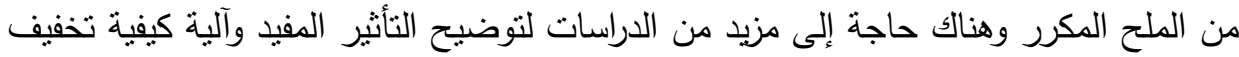

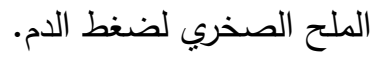

